\title{
Entre el olvido y la memoria
}

\section{Between oblivion and memory}

Asunción López Carretero *

Recibido: 11 de julio de 2021 Aceptado: 12 de julio de 2021 Publicado: 27 de julio de 2021

To cite this article: López Carretero, A. (2021). Entre el olvido y la memoria. Márgenes, Revista de Educación de la Universidad

de Málaga, 2 (2), 150-156

DOI: http://dx.doi.org/10.24310/mgnmar.v2i2.12978

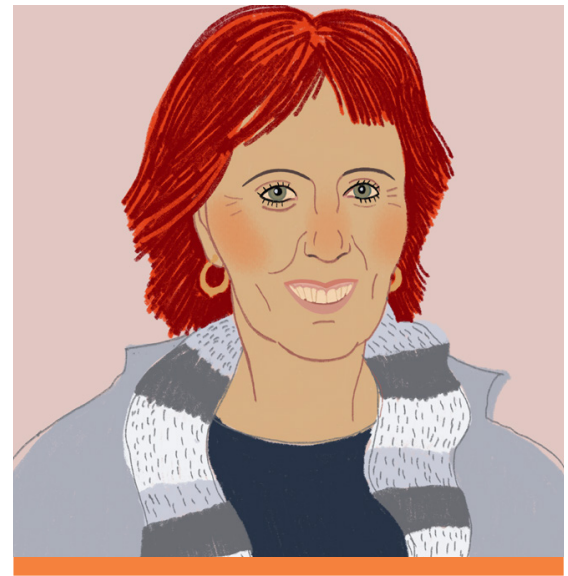

Asunción López Carretero

\section{RESUMEN}

Con la pandemia han saltado muchas de las costuras de nuestras sociedades, hasta el punto de que no solo hablamos de un problema sanitario sino de una auténtica crisis del modelo de civilización. La autora nos invita a pensar en ello tomando como hilo conductor las formas de representar y de vivir dos etapas de la vida especialmente castigadas en estos tiempos: la infancia y, como ella lo nombra, la edad avanzada.

Palabras clave: pandemia; desigualdad; relaciones intergeneracionales

\section{ABSTRACT}

With the pandemic, many of the seams in our societies have come apart, to the point that we are not only talking about a health problem but also about a real crisis in the model of civilisation. The author invites us to think about this, taking as a guiding thread the ways of representing and living two stages of life that are particularly punished in these times: childhood and, as she calls it, advanced age.

Keywords: pandemic; inequality; intergenerational relations

Con el acontecimiento de la pandemia han estallado fronteras que delimitaban nuestros espacios tanto físicos como psicosociales. En nuestra vida cotidiana, por ejemplo, la frontera entre escuela-familia y, más allá en el día a día, las fronteras espacio-temporales, se han modificado.

Se ha acuñado el término sindemia utilizado por Ubieto (2021) y otros autores para señalar que estamos no solo ante un problema sanitario, sino también y a la vez, frente a una crisis de formas de vida poco sostenibles tanto desde el 
punto de vista personal como común. De este modo, para quién lo quiere ver, esta crisis es una ocasión para vislumbrar algo más en esos pedazos en que se han roto nuestras rutinas cotidianas.

Las palabras con las que se describe la situación desde los discursos hegemónicos a veces son banales y otras solo se refieren a cifras. El cansancio, junto con la falta de palabras sensatas que den cuenta del dolor y las pérdidas de todo tipo que para cada quién ha significado la experiencia vivida, abonan el terreno para que el olvido haga su trabajo.

Por motivos diversos, ya que muy diferentes son las experiencias de las personas frente a una situación traumática, intentamos mirar para otro lado. Es humana la necesidad del olvido, pero me nacen algunas preguntas: ¿cómo sanar y transformar las huellas profundas que esta crisis está generando en nosotros haciendo tambalear los cimientos y las bases que conforman una vida humana digna? ¿Qué es lo esencial que ya estaba en una gran precariedad y que esta pandemia está poniendo de forma cruda ante nuestros ojos? Muchas de las estructuras que la pandemia ha derrumbado - o que están en proceso de probarse obsoletas - ya estaban debilitadas desde antes, como es el caso de ciertas formas de comunicación familiar, también ciertas prácticas en los espacios educativos, y una ausencia del sentimiento comunitario de interdependencia entre los seres humanos.

Han saltado a primer plano la miseria y las desigualdades que una política de las apariencias y del ocultamiento había intentado dejar en penumbra en favor de una sociedad fuertemente individualista y consumista. La sociedad líquida, como la denominó Bauman, mostró que había caído el paradigma opresor-oprimido desvelando que el mundo global desdibuja las relaciones de poder que cada vez son más sutiles y permeables. La miseria se presenta como circunstancial, es una cuestión de azar, y superarla una forma de valentía según los discursos dominantes. La alteridad, es decir el encuentro y complicidad con el otro diferente de mí, se ha sustituido por la figura del otro como enemigo potencial; lo singular se desgaja de lo común y cada persona es librada a su propia "suerte".

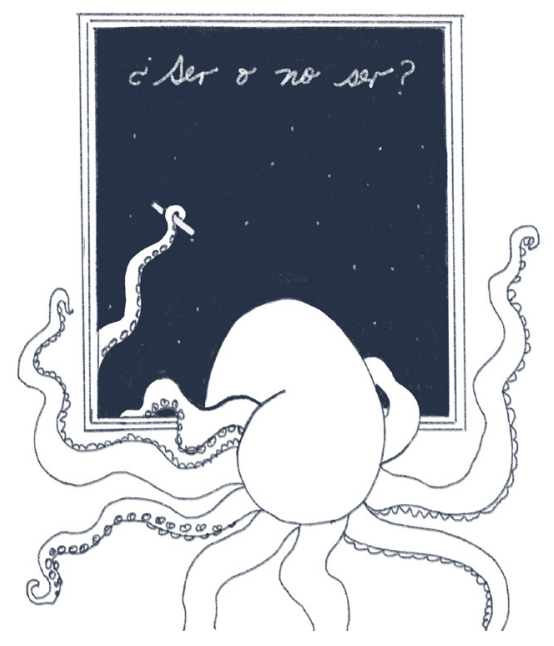




\section{"¿qué mundo queremos, siendo la infancia y la edad avanzada dos pilares fundamentales?"}

Junto a estas desigualdades y otras muchas, una de las cuestiones que ha estallado interpelándonos ha sido la construcción social que, en nuestras sociedades occidentales, responde al criterio de la edad. Una amiga muy querida, compañera de la facultad, y que ya no está entre nosotros (Caterina Lloret, profesora de la Universidad de Barcelona), decía que la edad es un secuestro. Es un secuestro en tanto que al partir de un dato de la biografía personal que responde a la biología, la sociedad establece unas prisiones homogeneizadoras que regulan sutilmente cómo vivir a cada edad. Además, funciona muy bien como velo encubridor de otras cuestiones más profundas, como la miseria, el abandono, la soledad... y la falta de horizonte para los más jóvenes. Y finalmente borra la pregunta por ¿qué mundo queremos, siendo la infancia y la edad avanzada dos pilares fundamentales?

La infancia es un mundo abierto de posibilidades a cultivar y cuidar; y las edades maduras un momento vital de una gran lucidez y experiencia elaborada durante todo un recorrido vital plagado de acontecimientos. Sin embargo, durante esta pandemia estamos viendo el destino que para muchas personas mayores supone el cumplir años. No ser "productivas" para el mercado y no poder ocultar cierta vulnerabilidad física y económica constituye una de esas prisiones. Cuando todas estas circunstancias concurren, el destino - en el mejor de los casos- es un geriátrico. También hemos podido ver las condiciones extremas en que viven muchas de estas personas, tanto por los escasos recursos públicos con los que cuentan los centros, como cuando algunas de ellas sobreviven solas en sus domicilios.

El territorio ha sido y es otro dato que aprisiona. El contexto vital de origen funciona también como elemento a veces determinante. Las fronteras han sido demolidas por el virus, sin embargo, han crecido las murallas que separan a los pueblos, a las personas, a las prácticas de alteridad que humanizan las relaciones. Nos encontramos así con una diversidad de momentos vitales y experienciales con diferencias de orígenes y culturas, pero todos ellos con una única unidad de medida: la productividad. 
La infancia se considera una preparación en la que muchas veces se borra la espontaneidad que no encuentra cauces para desarrollarse; la juventud un tránsito hacia el mercado; las edades maduras un "fuera de campo". En todos estos momentos observamos una pérdida inquietante del valor simbólico de la vida que da sentido a la existencia de cada una y cada uno.

¿Por qué hablar de todo lo anterior en un espacio de educación?

La pandemia no ha cogido a nadie con buen pie. Los bebes porque en muchos casos no han podido disfrutar del aire libre y del juego con tranquilidad. La crianza ha sido compleja. Lo que hemos decidido llamar "infancia” también ha sufrido sus consecuencias: o bien se han quedado clausurados en casa o han ido a la escuela de forma poco espontánea por las medidas sanitarias. Los jóvenes, apartados de sus iguales, en situaciones de precariedad laboral, sin posibilidad de vivir de forma autónoma, también se han sentido muy perdidos. Incluso aquellos que han tenido o tienen la oportunidad de acceder a la universidad han entrado en un espacio nuevo en condiciones poco saludables.

Los discursos hegemónicos, de forma sutil, van transmitiendo con gestos, palabras e imágenes una infancia cristalizada y homogénea. Cabe recordar — por insistente - el tópico de que los niños y niñas van a la escuela para estar con sus amigos y amigas. Cosa que es cierta solo en parte y que simplifica tanto a la infancia en su diversidad como al profesorado en su función. ¿Es la escuela un almacén? ¿Un parque? ¿O sirve para cubrir todos los déficits de una sociedad profundamente desigual? Desigual que no debe confundirse con diversa, como a veces nos hacen creer.

Los jóvenes son noticia cuando generan "conflicto". Desconfiados frente al mundo adulto, son a menudo demonizados en sus comportamientos, pero sus actitudes no nos conducen a abrirnos preguntas. Rápidamente los comportamientos de niños y jóvenes que no encajan o que muestran un alto grado de malestar se llevan al campo de la salud mental, y con ello, se convierten en cuestiones individuales fácilmente estigmatizantes. 


\section{"'Hacer escuela' es crear múltiples formas de sostener una relación educativa"}

La responsabilidad y la ética de lo común quedan así de nuevo ocultas. Se trata de apagar fuegos, no de analizar también y a la vez, las condiciones de vida en las que emergen estos desencajes.

Una cuestión importante es que no olvidemos que la escuela nunca cerró durante la pandemia en todo el mundo. Lo observamos si nos detenemos en las diversas formas de "hacer escuela" que han surgido más allá de fronteras institucionales, espaciales y temporales; nos asombramos ante la cantidad de maneras que han emergido mostrando grandes dosis de creatividad. Desde la escuela infantil hasta la universidad.

"Hacer escuela" es crear múltiples formas de sostener una relación educativa como, por ejemplo, el caso de maestras que en tiempos de confinamiento han aprovechado la comida que se llevaba a las casas en lugares desasistidos para poner escritos con algunas indicaciones de estudio, o la creación de bibliotecas ambulantes, y otras muchas experiencias. Estas y otras prácticas las hemos descubierto en multiplicidad de realidades en las que ha ido tomando forma ese "hacer escuela" que se apoya en el deseo de hacer crecer a las criaturas, de entender profundamente que la cultura abre posibilidades, nutre y genera pasajes e itinerarios de vida. En definitiva, nos humaniza. También han sucedido momentos y experiencias de oscuridad, de exigencia en estas épocas inciertas. Han aparecido tensiones que desvelan diferentes formas de entender lo educativo. Resumiendo, sin querer esquematizar, diré que frente a la incertidumbre ha surgido también una intensificación de modelos educativos enfocados al rendimiento.

En el presente nos movemos entre el olvido y la memoria y creo, parafraseando a Ubieto (2021), que "Lo primero es hacernos cargo que esto no era un paréntesis. (...) Parecen malas noticias, pero quizás no lo son tanto. Nos devuelven el control, la capacidad de hacer nuevos planes, ajustados a las posibilidades, pero más orientados a la resonancia (conectar con nuestro deseo) que a la aceleración (producir y rendir sin obstáculos)” (blog Ned Ediciones, 17 de febrero de 2021). Es 
decir, se trata de una invitación a no desconectarnos de esos deseos genuinos que han nacido en la pandemia.

Suscribo con Ubieto este enfoque en el que una de las claves es algo aparentemente tan simple como "recuperar la conversación": enfocarse en la escucha y abandonar de una vez por todas la comunicación unilateral o una cierta "pose" discursiva (herencia de nuestras máscaras en las redes sociales). No es necesario comprender para acompañar, es decir, no se trata de consensuar borrando las diferencias. Ahora más que nunca los vínculos se tienen que construir sobre este sentido de acompañamiento y de comunidad, generando complicidades sin borrar las diferencias.

En la educación, en las escuelas, en la universidad, se dan ocasiones de oro para generar ese movimiento entre el olvido y la memoria, recuperando recuerdos y transformándolos en valor simbólico, en cultura del tiempo con sentido; tiempo de la vida con sus preguntas e inquietudes, para salir del aislamiento propiciando el deseo de encuentro, para generar vínculos verdaderos entre generaciones en el presente y en el curso de la historia, vivificando la relación con el saber en nuestras vidas. Para reestablecer conexiones con distintos momentos culturales y contextuales que abren sentidos al presente. Para salir de las burbujas en las que ya vivíamos sin darnos cuenta antes de la pandemia.

La educación es la oportunidad para generar tránsitos y relaciones entre los diferentes momentos vitales poniendo especial atención en la infancia como inicio y en los procesos vitales que le siguen con sus discontinuidades, pero con la riqueza que emana de cada momento. También es una oportunidad para reconocer la sabiduría de los mayores como un tesoro a custodiar y a reinventar. Recuerdo experiencias de historia oral en los institutos en las que el alumnado recogía testimonios de sus padres y abuelos, una forma de enseñar historia muy fértil.

El momento presente es una ocasión para recuperar los riesgos y las ganancias del "cara a cara”, de la 
"Y, de este modo, volver a coser los desgarros, pero tejiendo algo nuevo, algo siempre en movimiento entre el olvido y la memoria" presencia encarnada, poniendo cuerpo y espontaneidad a nuestros espacios de relación, abriéndonos al imprevisto, a la sorpresa y al asombro. La presencia, entendida en sentido amplio como un estar ahí y buscar prácticas colaborativas para mantener fuertes los vínculos comunitarios en tiempos de obligado distanciamiento social, será decisiva en la construcción del mundo pos-COVID (Ubieto opus cit.).

En definitiva, buscar nuevas fórmulas, dentro de las posibilidades actuales, para seguir alimentando lo que sí se ha constatado como prioritario para resistir con mejores armas una situación como la pandemia global: un buen entramado de relaciones interpersonales y comunitarias. Cultivar una conexión profunda entre lo singular y lo común para situarnos en esta interdependencia que atraviesa fronteras personales, institucionales, culturales... Y, de este modo, volver a coser los desgarros, pero tejiendo algo nuevo, algo siempre en movimiento entre el olvido y la memoria; cruzando los hilos y los colores de otros modos, abiertos a una esperanza advertida, es decir, una esperanza que se apoya en la elaboración de la experiencia vivida sin negarla ni magnificarla.

\section{REFERENCIAS}

Editorial (17 de febrero de 2021). El impacto psicológico de la pandemia y los nuevos retos socioafectivos. El blog de NED Ediciones. https://nededicionesblog.wordpress. com/2021/02/17/el-mundo-pos-covid-jose-ramonubieto/

Ubieto, J. R: (2021). El mundo post-Covid. NED Ediciones. 